\title{
PROCEDIMENTOS DE AUDITORIA APLICADOS PELAS EMPRESAS DE AUDITORIA INDEPENDENTE DE SANTA CATARINA EM ENTIDADES DO TERCEIRO SETOR
}

\section{AUDIT PROCEDURES APPLIED BY THE INDEPENDENT AUDITORS OF SANTA CATARINA COMPANIES IN THIRD SECTOR ENTITIES}

\author{
PAULO ROBERTO DA CUNHA
Professor da Universidade do Estado de Santa Catarina, UDESC \\ Doutorando em Ciências Contábeis e Administracãa pela Universidade Regional de \\ Blumenau - FURB
Blumenau, SC - Brasil \\ E-mail: pauloccsa@furb.b \\ SILENE RENGEL \\ Professora da Faculdades AČ̃̃ - Sistema de Ensino Energia \\ Mestrado em Ciências Contábeis pela Universidade Regional de Blumenau, FURB \\ Blumenau, SC - Brasil \\ E-mail: silener@al.furb.br
}

\author{
ROBERTO CARLOS KLANN \\ Doutorando em Ciências Contábeis e Administração pela Universidade Regional \\ Blumenau, SC - Brasil
E-mail: rklann@al.furb.br \\ JORGE EDUARDO SCARPIN \\ Professor da Universidade Regional de Blumenau, FURB, Brasil. \\ Doutorado em Controladoria e Contabilidade pela Universidade de São Paulo \\ Blumenau, SC - Brasil \\ E-mail: jorgescarpin@furb.br
}

\begin{abstract}
RESUMO
O objetivo do artigo é identificar quais são os procedimentos de auditoria utilizados pelas empresas de auditoria independente estabelecidas em Santa Catarina (SC) nas entidades do Terceiro Setor. Realizou-se uma pesquisa descritiva, de levantamento e com abordagem quantitativa. A populacão corresponde as 23 empresas de auditoria estabelecidas em SC e com registro na Comissão de Valores Mobiliários. A amostra, por acessibilidade, representou $26 \%$ empresas de auditoria. Como instrumento de pesquisa utilizou-se um questionário com perguntas abertas e fechadas, cujos respondentes correspondiam a cargos superiores a auditores seniores. Os resultados demonstram que os testes de observância mais utilizados são o exame documental e o teste de segregacão de funções, utilizado por todas as empresas de auditoria. As áreas de compras e de pessoal são as áreas com maior aplicacão dos testes de observância. Quanto aos testes substantivos mais utilizados, constatou-se que são os testes de confirmação externa, o exame e contagem física, o exame de documentos originais e o exame de escrituração. Com maior aplicacão nas áreas relacionadas com as disponibilidades, com os estoques e com as contas a recéber. Concluiu-se também que os resultados convergiram com a pesquisa de Cunha, Beuren e Hein (2006) nos aspectos relacionados aos testes mais e menos utilizados, e nas áreas que mais e menos são aplicados estes procedimentos de auditoria, tanto para os testes de observância quanto aos substantivos. Isso sinaliza que para as empresas de auditoria de SC os procedimentos de auditoria não diferem para uma auditoria das demonstrações contábeis com foco no terceiro setor em relação aos outros setores.
\end{abstract}

Palavras-chave: Auditoria. Procedimentos de auditoria. Terceiro Setor.

\section{ABSTRACT}

The aim of this paper is to identify what are the audit procedures used by independent auditing companies established in Santa Catarina (SC) on the Third Sector entities. This is a descriptive study, a survey and a quantitative approach. The population amounts to 23 audit companies established in SC State and registered at the Securities Commission. The sample, due to reasons of accessibility ${ }_{2}$ comprehends $26 \%$ of audit companies. The instrument used for the collection of data consisted of a questionnaire with both open and closed questions, which the respondents corresponded to positions above senior auditors. The results show that observance tests most commonly used are document review and the test of segregation of functions used by all audit companies. The sales and purchase areas and the personal area are most frequently used in observance tests. As for more substantive used tests, it was found that external confirmation tests, examination and physical count, examination of original documents and the examination of bookkeeping are the most common used. With wider application in areas related to available cash, with stocks and accounts receivable. It was also concluded that the results of this research have converged to research by Cunha, Beuren and Hein (2006) on aspects related to testing the most and least used, and in areas that are most and least implemented these audit procedures both for testing compliance as to nouns. This indicates that for the SC audit companies the procedures did not differ for an audit of financial statements with a focus in the third sector in relation to other sectors.

Keywords: Auditing. Audit procedures, Third Sector. 


\section{INTRODUÇÃO}

As entidades do terceiro setor inserem-se na sociedade com ações voltadas às mudanças sociais em aspectos na qual o Estado ou o setor privado não atendem na sua plenitude. As entidades do terceiro setor são criadas para atender segmentos como habitação, saúde, cultura e recreação, assistências social, meio ambiente e proteção aos animais, desenvolvimento e defesa dos direitos, religião entre outros.

Conforme levantamento realizado pelo Instituto Brasileiro de Geografia e Estatística - IBGE (2002), concluiu-se que em 2002 existiam no país cerca de 276 mil entidades sem fins lucrativos, representando $5 \%$ do total das organizações (privadaslucrativas, privadas-sem fins lucrativos e públicas) formalmente cadastradas no país.

Dada a sua representatividade e seu o crescimento no Brasil, estudos sobre esse segmento ganhou força com o surgimento de centros de estudos específicos como CETS - Centro de Estudos do Terceiro Setor - criado em 1994, pela FGV (Fundação Getúlio Vargas) - EAESP (Escola de Administração de Empresas de São Paulo) e o CEATS - Centro de Empreendedorismo Social e Administração em Terceiro Setor constituído como programa institucional em 1998, com suporte da FIA (Fundação Instituto de Administração) e da FEA/USP (Faculdade de Economia, Administração e Contabilidade da Universidade de São Paulo). (BARRAGAN, 2005)

Devido às ações das entidades de terceiro setor serem de interesse público, a transparência das atividades e da gestão dessas entidades é importante principalmente por terem como fonte de recursos para seu custeamento, as doações, subvenções e contribuições de voluntários. (RENGEL et al, 2009).

Uma das formas dessas entidades do terceiro setor ter transparência nas atividades e na gestão é por meio de prestações de contas. Essa prestação de contas pode ser realizada por meio da publicação das demonstrações contábeis. Para dar maior credibilidade e lisura a essas demonstrações contábeis, diversas entidades contratam serviços de auditoria independente.

A auditoria independente audita as demonstrações com o intuito de atestar aos diversos usuários, que as demonstrações contábeis representam em seus aspectos relevantes, a situação financeira e patrimonial das entidades. Para tanto, o auditor independente irá aplicar diversos procedimentos de auditoria para que, ao final de seu trabalho, tenha reunido evidências suficientes que dê sustentação ao seu parecer. Os procedimentos de auditoria aplicados pelas empresas de auditoria independente já foram estudados por Cunha, Beuren e Hein (2006), porém num universo geral de empresas.

Nas entidades do terceiro setor observam-se particularidades que as distingue das empresas em geral. Um aspecto observado nas entidades do terceiro setor é a sua manutenção por meio de doações de empresas privadas, públicas e da população 
geral. Para tanto, espera-se que os procedimentos de auditoria mais utilizados sejam os exames físicos, documentais e de escrituração e que as áreas com maior aplicação de testes sejam as de receitas, doações e disponibilidades.

Assim, levanta-se a seguinte questão: quais são os procedimentos de auditoria aplicados pela empresa de auditoria independente nas entidades do Terceiros Setor? Nesse contexto, o objetivo do artigo é identificar quais são os procedimentos de auditoria utilizados pelas empresas de auditoria independente estabelecidas em Santa Catarina nas entidades do Terceiro Setor. 0 artigo justifica-se pelo fato de que as entidades do terceiro setor possuem características diferenciadas das demais entidades podendo revelar procedimentos de auditoria diferenciados ou priorizados pelos auditores independentes na condução de seus trabalhos.

O estudo está estruturado em seis tópicos, iniciando com essa introdução. Em seguida aborda sobre os procedimentos de auditoria, com ênfase nos testes substantivos e nos testes de observância. Na sequência, discorre-se sobre as entidades do Terceiro Setor e se expõe o contexto da auditoria independente nesse setor. Após, descreve-se o método e as técnicas da pesquisa. Segue com a descrição e análise dos dados, mostrando as características das empresas de auditoria independente pesquisadas, os testes de auditoria mais utilizados e as áreas de maior aplicação focada no Terceiro Setor. Por fim, apresentam-se as conclusões da pesquisa realizada e as referências que o fundamentam.

\section{PROCEDIMENTOS DE AUDITORIA}

A auditoria das demonstrações contábeis é o trabalho realizado por auditor independente, que após aplicação de um conjunto de procedimentos por ele adotado, emite um parecer sobre a adequação das demonstrações contábeis analisadas. 0 parecer do auditor independente é elaborado observando-se as demonstrações contábeis quanto à adequação aos Princípios Fundamentais de Contabilidade e as Normas Brasileiras de Contabilidade e demais legislações pertinentes.

Para que o auditor possa suportar sua opinião por meio do parecer, o mesmo deve aplicar diversos procedimentos para testar a adequação das demonstrações contábeis. Nesse sentido, Attie (1998, p. 131), menciona que "os procedimentos de auditoria são as investigações técnicas que, tomadas em conjunto, permitem a formação fundamentada da opinião do auditor sobre as demonstrações financeiras ou sobre o trabalho realizado".

Boynton, Johnson e Kell (2002, p. 209) mencionam que "procedimentos de auditoria são os métodos que o auditor utiliza para coletar e avaliar material de evidência suficiente e competente".

Cunha, Beuren e Hein (2006, p. 54) destacam que "para o auditor chegar ao seu objetivo final da auditoria, que é o de formar uma opinião, de forma imparcial, 
necessita utilizar procedimentos adequados. Estes devem proporcionar a reunião de evidências materiais e necessárias à formação de sua opinião".

Os procedimentos de auditoria são divididos em testes de observância (controle) e testes substantivos. Os testes substantivos por sua vez dividem-se em testes de detalhes (de classes de transações, de saldos de contas e de divulgações) e procedimentos analíticos substantivos. (CFC, 2009).

Os testes de observância são abordados em diversas literaturas como testes de aderência ou testes de controle. A Resolução 1.214 de 2009 do CFC descreve que o "teste de controle é o procedimento de auditoria planejado para avaliar a efetividade operacional dos controles na prevenção ou detecção e correção de distorções relevantes no nível de afirmações”.

Andrade (1988, p. 13) explica que os testes de observância "são amostras retiradas de uma população, com a finalidade de determinar, até que ponto os procedimentos, ao serem implantados, observam as especificações do sistema”.

Santi (1988, p. 88), testes de observância constituem-se no “conjunto de procedimentos de auditoria destinados a confirmar se as funções críticas de controle interno, das quais o auditor dependerá nas fases subsequentes da auditoria, estão sendo efetivamente executadas".

Os teste de controle são constituídos por procedimentos voltados a avaliação da eficácia e implementação dos controles internos. (MESSIER Jr, 2003). Do exposto, verifica-se que os testes de observância são aplicados com a finalidade de avaliar se os procedimentos de controles internos definidos pela administração são adotados e cumpridos com a devida segurança e confiabilidade necessária para proteção do patrimônio da entidade.

Os controles internos são estabelecidos em áreas da entidade mais expostas aos riscos, julgadas importantes pela sua complexidade, pela sua importância na atividade da entidade ou pelo volume de transações que nela ocorrem. Consequentemente, o auditor ao efetuar o planejamento e extensão de seus trabalhos, deve levar em consideração tais aspectos e com base nestes, realizar a aplicação dos testes de observância.

A aplicação dos testes de observância justifica-se pelo fato de que os registros contábeis e por consequência os saldos apresentados nas demonstrações contábeis, originam-se dos controles internos. 0 auditor independente ao analisar o sistema contábil e de controles internos, tem condições de definir quais os procedimentos de auditoria devem ser utilizados nos testes de observância. Nesse sentido, o Quadro 1 , expõe os testes de observância contemplados na literatura. 


\begin{tabular}{|c|c|}
\hline TESTE & DESCRIÇÃO \\
\hline $\begin{array}{l}\text { Teste de } \\
\text { assinaturas }\end{array}$ & $\begin{array}{l}\text { Consiste na verificação e confrontação das assinaturas dos responsáveis em } \\
\text { documentos da empresa. }\end{array}$ \\
\hline $\begin{array}{l}\text { Teste de } \\
\text { aprovações }\end{array}$ & $\begin{array}{l}\text { Verificacãa de que a transação e a documentação suporte foram efetivamente } \\
\text { aprovadas por pessoas em niveis adequados e responsáveis. }\end{array}$ \\
\hline $\begin{array}{l}\text { Exame } \\
\text { documental }\end{array}$ & $\begin{array}{l}\text { Compreende avaliação dos procedimentos de controles e monitoramentos } \\
\text { representados pelos documentos. E a técnica que consome mais horas da } \\
\text { auditoria. }\end{array}$ \\
\hline $\begin{array}{l}\text { Teste de } \\
\text { segregação de } \\
\text { função }\end{array}$ & $\begin{array}{l}\text { Consiste em verificar se uma mesma pessoa tem acesso aos ativos e, aos } \\
\text { registros contábeis, devido ao fato dessas funções serem incompativeis } \\
\text { dentro do sistema de controle interno. }\end{array}$ \\
\hline $\begin{array}{l}\text { Teste de } \\
\text { salvaguarda }\end{array}$ & Verificação da forma de controle, armazenamento e proteção de ativos. \\
\hline \multirow[t]{2}{*}{$\begin{array}{l}\text { Integridade } \\
\text { da sequêencia } \\
\text { numérica }\end{array}$} & $\begin{array}{l}\text { Consiste na observação da sequência numérica dos documentos e sua } \\
\text { coerência entre data de emissão ou cancelamento dos documentos. }\end{array}$ \\
\hline & $\begin{array}{l}\text { Verificação da autenticidade do cancelamento de documentos, bem como } \\
\text { dos motivos do cancelamento, principalmente quando utilizados em } \\
\text { demasia. }\end{array}$ \\
\hline Inquérito & $\begin{array}{l}\text { Consiste na formulação de perguntas e na obtenção de respostas satisfatórias. } \\
\text { Pode ser utilizado por meio de declarações formais, conversaç̃es normais } \\
\text { ou sem compromisso. As respostas obtidas devem ser examinadas para a } \\
\text { confirmação das informações recebidas. }\end{array}$ \\
\hline $\begin{array}{l}\text { Aplicação de } \\
\text { questionário }\end{array}$ & $\begin{array}{l}\text { Compreende o meio de obtenção de evidência por correio ou à distância. } \\
\text { Este procedimento é mais utilizado quando se necessita obter informações } \\
\text { limitadas e específicas dentre um universo de pessoas. }\end{array}$ \\
\hline $\begin{array}{l}\text { Conferência } \\
\text { de cálculos }\end{array}$ & $\begin{array}{l}\text { É a constatação da adequação das operações aritméticas. Esta técnica } \\
\text { é amplamente utilizada em virtude de a quase totalidade das operações } \\
\text { dentro da empresa estar voltada para este processo contábil. }\end{array}$ \\
\hline $\begin{array}{l}\text { Exame e } \\
\text { contagem } \\
\text { física }\end{array}$ & $\begin{array}{l}\text { Verificação in loco que proporcionará a existência física do objeto ou do } \\
\text { item examinado. Nesse teste observa-se a quantidade, a constatação } \\
\text { visual, identificação, autenticidade e qualidade. }\end{array}$ \\
\hline
\end{tabular}

\section{Quadro 1 - Teste de observância}

Fonte: adaptado de Attie (1998) e Imoniana (2001).

O auditor independente fará uso de um ou outro teste de observância conforme o objetivo e finalidade do trabalho. Os resultados obtidos dos testes de observância, quanto à qualidade e o nível de confiança dos controles internos, determinada a extensão e a intensidade da aplicação dos testes substantivos. Lima (2002, p. 102) destaca que "concluídos os testes de aderência, é obtido o conhecimento, por parte do auditor, quanto ao grau de confiança a ser depositado nos controles internos da entidade auditada". O mesmo autor ressalta que "esse trabalho minimiza esforços da auditoria, no que se refere à extensão e profundidade dos testes substantivos".

Os testes de observância relacionam-se inversamente aos testes substantivos. Quanto maior a confiança constatada nos controles internos, menor a extensão e profundidade na aplicação dos testes substantivos. Por outro lado, maior será 
a aplicação dos testes substantivos, quando constatado pelo auditor um controle interno fragilizado. (CUNHA, BEUREN e HEIN, 2006)

Para Messier Jr (2003, p.199) os testes substantivos "são procedimentos de auditoria realizados para testar erros materiais numa classe de transações e nas demonstrações financeiras".

Lima (2002, p. 105) expõe que "os testes substantivos objetivam assegurar ao auditor a suficiência, a exatidão e o devido suporte documental para os saldos dotados de relevância, apresentados nas demonstrações contábeis”. Do exposto, verifica-se que os testes substantivos são aplicados para identificar a ocorrência ou não de erros na contabilização das transações contábeis e consequentemente suas implicações nos saldos das contas das demonstrações contábeis. De maneira mais ampla, a aplicação dos testes substantivos visam atender aos objetivos expostos no Quadro 2.

\begin{tabular}{|c|c|}
\hline OBJETIVO & DESCRIÇÃO \\
\hline Existência & se o componente patrimonial existe em certa data \\
\hline Direitos e obrigações & se efetivamente existentes em certa data \\
\hline Ocorrência & se a transação de fato ocorreu \\
\hline Abrangência & se todas as transações estão registradas \\
\hline $\begin{array}{c}\text { Mensuração, } \\
\text { apresentação e } \\
\text { divulgação }\end{array}$ & $\begin{array}{c}\text { se os itens estão avaliados, divulgados, classificados e descritos de } \\
\text { acordo com os Princípios Fundamentais de Contabilidade e as Normas } \\
\text { Brasileiras de Contabilidade }\end{array}$ \\
\hline
\end{tabular}

Quadro 2 - Objetivos do auditor na aplicação dos testes substantivos

Fonte: CFC (1997).

Na aplicação dos testes substantivos, com a abrangência exposta no Quadro 2, o auditor, a exemplo dos testes de observância, utiliza também de procedimentos de auditoria, destacados no Quadro 3.

\begin{tabular}{|c|c|}
\hline TESTE & DESCRIÇÃO \\
\hline $\begin{array}{l}\text { Exame e } \\
\text { contagem física }\end{array}$ & $\begin{array}{c}\text { Verificação in loco que proporcionará a existência física do objeto ou do item examinado. } \\
\text { Nesse teste observa-se a quantidade, a constatação visual, identificação, autenticidade e } \\
\text { qualidade. }\end{array}$ \\
\hline $\begin{array}{l}\text { Confirmação } \\
\text { externa }\end{array}$ & $\begin{array}{c}\text { É o procedimento pelo qual o auditor procura obter uma informação externa, comumente } \\
\text { designado de circularização ou confirmação de terceiros e referente a determinados } \\
\text { fatos que esse "terceiro" possa atestar por meio de documento formal. }\end{array}$ \\
\hline Conciliações & $\begin{array}{c}\text { São reconciliações entre o saldo contábil e o saldo de determinado documento, como } \\
\text { extrato bancário, planilha de empréstimo, ou outros documentos internos ou externos à } \\
\text { empresa. }\end{array}$ \\
\hline $\begin{array}{l}\text { Exame dos } \\
\text { documentos } \\
\text { originais }\end{array}$ & $\begin{array}{l}\text { É o procedimento de auditoria voltado para o exame de documentos que comprovem } \\
\text { transações comerciais ou de controle. }\end{array}$ \\
\hline $\begin{array}{l}\text { Conferência de } \\
\text { cálculos }\end{array}$ & $\begin{array}{c}\text { Técnica igual aplicada ao teste de observância que visa a constatação da adequação das } \\
\text { operações aritméticas. }\end{array}$ \\
\hline
\end{tabular}

\section{Quadro 3 - Testes substantivos}


continuação

\begin{tabular}{|c|c|}
\hline TESTE & DESCRIÇÃO \\
\hline $\begin{array}{l}\text { Exame de } \\
\text { escrituração }\end{array}$ & $\begin{array}{l}\text { É a técnica utilizada para a constatação da veracidade das informações contábeis. Este } \\
\text { é o procedimento de auditoria usado para o levantamento de análises, composições de } \\
\text { saldo, conciliações etc. }\end{array}$ \\
\hline $\begin{array}{l}\text { Exame de } \\
\text { registros } \\
\text { auxiliares }\end{array}$ & $\begin{array}{c}\text { É utilizada como suporte de autenticidade dos registros principais examinados. O uso } \\
\text { dessa técnica deve sempre ser conjugado com o uso de outras que possam comprovar a } \\
\text { fidedignidade do registro principal. }\end{array}$ \\
\hline Inquérito & $\begin{array}{c}\text { Da mesma forma que nos testes de observância, consiste na formulação de perguntas e } \\
\text { na obtenção de respostas satisfatórias, por meio de declarações formais, conversações } \\
\text { normais ou sem compromisso. }\end{array}$ \\
\hline $\begin{array}{l}\text { Investigação } \\
\text { minuciosa }\end{array}$ & $\begin{array}{l}\text { É o exame em profundidade da matéria auditada, que pode ser um documento, uma } \\
\text { análise, uma informação obtida, entre outras. }\end{array}$ \\
\hline $\begin{array}{l}\text { Correlação das } \\
\text { informações } \\
\text { obtidas }\end{array}$ & $\begin{array}{l}\text { É o relacionamento harmônico do sistema contábil de partidas dobradas. Durante } \\
\text { os trabalhos, ao auditor executará serviços que terão relações com outras áreas do } \\
\text { balanço da demonstração do resultado do exercício. A medida que for observado o } \\
\text { relacionamento entre estas, o auditor estará efetuando o teste de correlação das } \\
\text { informações. }\end{array}$ \\
\hline Observação & $\begin{array}{l}\text { Compreende o acompanhamento dos procedimentos que o auditado efetua para } \\
\text { comprovação dos fatos colhidos em outros procedimentos de auditoria aplicados. }\end{array}$ \\
\hline
\end{tabular}

Fonte: adaptado de Attie (1998) e Imoniana (2001).

Os testes substantivos dividem-se em testes de detalhes das transações e saldos e procedimentos de revisão analítica. Os testes de detalhes das transações e saldos são aplicados com a finalidade de reunir evidências que demonstrem que as transações e os saldos demonstrados nas demonstrações contábeis estão corretos.

Os procedimentos de revisão analítica, conforme Santi (1988, p. 129) correspondem "a uma modalidade de testes substantivos de elementos econômicofinanceiros, executados por meio de análise e comparação do relacionamento entre eles". Santi (1988, p. 129) complementa que "se os procedimentos de revisão analítica acusarem variações inesperadas no relacionamento entre elementos, ou a inexistência de flutuações que seriam esperadas, ou ainda outra alterações de origem inusitada, suas causas devem ser investigadas".

A finalidade dos testes analíticos é encontrar situações anormais e significativas constatadas nos saldos das demonstrações contábeis, que podem demonstrar áreas com problemas, onde o auditor deverá despender mais tempo de auditoria.

Os testes analíticos podem ser aplicados no planejamento dos trabalhos de auditoria, no momento em que o auditor identifica os prováveis problemas e riscos aparentes de controles internos. Outro momento de aplicação dos testes analíticos é no decorrer dos trabalhos, onde são aplicados, quando da obtenção de alguma evidência, a fim de dar suporte aos controles internos (CUNHA, BEUREN e HEIN, 2006). 


\section{ENTIDADES DO TERCEIRO SETOR E A AUDITORIA}

O Terceiro Setor consiste em organizações cujos objetivos principais são sociais ao invés de econômicos, portanto sua essência engloba associações, organizações filantrópicas, beneficentes e de caridade, organizações não governamentais (ONG), fundações privadas, organizações sociais e organizações da sociedade civil de interesse público (OSCIP), dentre outros (ALBUQUERQUE, 2007).

O Primeiro Setor é o Estado. O Segundo Setor é o Mercado, ou seja, as empresas privadas que operam com o objetivo de gerar lucros, que podem ser reinvestidos ou distribuídos aos proprietários ou acionistas. Já o Terceiro Setor encontra-se entre o Primeiro e o Segundo Setor, possui características de ambos, pois promove e executa políticas públicas, sem fito de lucro, e possui natureza privada sendo formado por sociedades civis organizadas (SOARES, 2006).

As entidades constituídas neste setor são definidas por Olak e Nascimento (2006, p. 6) como “instituições privadas com propósitos específicos de provocar mudanças sociais e cujo patrimônio é constituído, mantido e ampliado a partir de contribuições, doações e subvenções e que, de modo algum, se reverte para os seus membros ou mantenedores". As principais características atribuídas às entidades do Terceiro Setor são expostas no Quadro 4:

\begin{tabular}{|c|c|}
\hline \multicolumn{2}{|c|}{ CARACTERÍSTICAS ATRIBUÍDAS ÁS ENTIDADES DO TERCEIRO SETOR } \\
\hline 1. Objetivos institucionais & - Provocar mudanças sociais \\
\hline $\begin{array}{l}\text { 2. Principais fontes de recursos } \\
\text { financeiros e materiais }\end{array}$ & $\begin{array}{c}\text { 口 Doações, contribuiçõos, subvenções e prestação de } \\
\text { serviços comunitários }\end{array}$ \\
\hline 3. Lucro & $\begin{array}{l}\text { प Meio de atingir os objetivos institucionais e não um } \\
\text { fim }\end{array}$ \\
\hline 4. Patrimônio/Resultados & 口 Não há participação/distribuição aos provedores \\
\hline 5. Aspectos fiscais e tributários & ๑ Normalmente são imunes ou isentas \\
\hline 6. Mensuração do resultado social & $\square$ Difícil de ser mensurado monetária e economicamente \\
\hline
\end{tabular}

Destaca-se no Quadro 1, dentro das características do Terceiro Setor, que as principais fontes de recursos financeiros e materiais são oriundos de doações, contribuições, subvenções e prestação de serviços comunitários. Nesse sentido, como os recursos advêm de terceiros em forma de doações e subvenções, em parte da sociedade, cabe a entidade prestar contas à sociedade. Da mesma forma têm-se os aspectos fiscais e tributários, que no Terceiros Setor, de forma geral são isentos ou imunes. Essa prestação de contas é acompanhada das demonstrações contábeis juntamente com o parecer de auditoria independente.

A figura da auditoria independente nas entidades do terceiro setor em muitas regulamentações é indispensável. Nesse sentido, o Decreto 2.536/98 que dispõe da concessão de Certificado de Entidade de Fins Filantrópicos pelo Conselho Nacional 
de Assistência Social (CNAS) também faz menção da necessidade da auditoria independente, quando expõe em seu art. $5^{\circ}$ que "o CNAS somente apreciará as demonstrações contábeis e financeiras, se tiverem sido devidamente auditadas por auditor independente legalmente habilitado junto aos Conselhos Regionais de Contabilidade".

0 art. $4^{\circ}$ da lei 9.790/99 que dispõe sobre as OCIPS, menciona que dentre as normas a serem observadas pela entidade devem ser "a realização de auditoria, inclusive por auditores externos independentes se for o caso, da aplicação dos eventuais recursos objeto do termo de parceria”. Porém, não somente por força de lei deve-se aplicar a auditoria nas entidades do Terceiro Setor. Conforme a KPMG (2004) a auditoria no terceiro setor pode ajudar a instituição nos seguintes aspectos: a) melhorar o nível dos controles internos; b) buscar formas alternativas de geração de renda e desvincular-se de uma situação passiva de recebimento de doações; c) usar a auditoria como ferramenta de marketing e relacionamento com o público externo; d) usar ferramentas gerenciais no processo de administração do negócio; e) incentivar o treinamento e a capacitação dos profissionais das áreas Administrativa e Financeira, melhorando o nível da Controladoria, e; f) divulgar dados do balanço social e outros indicadores operacionais as demonstrações financeiras (transparência).

A KPMG (2006) realizou uma pesquisa com entidades do terceiro setor que atuam em diversas áreas, como: educação, saúde, assistência social, inclusão social, reabilitação, incentivo a gestão e empreendedorismo, com auditoria independente a mais de um ano. O objetivo dessa pesquisa foi o de avaliar se as entidades do Terceiro Setor que possuem processo de auditoria, efetuado por auditores externos independentes, perceberam melhorias em diversos aspectos e áreas de atuação. Diversos pontos mostraram-se com uma aprovação acima de 50\%, dentre eles: a) melhora nos controles internos da entidade; b) melhoria no relacionamento com parceiros, doadores e financiadores; c) melhora na imagem da empresa; d) maior facilidade no processo de aprovação de contas junto aos conselheiros; d) melhoria no relacionamento e na facilidade de captação de recursos junto aos bancos; e) melhoria nas práticas contábeis da entidade.

Assim, percebe-se que a realização de auditoria independente em entidades do Terceiro Setor pode trazer benefícios e não ser apenas uma exigência regulamentar. No processo de auditoria, estão os procedimentos de auditoria que o auditor faz uso para dar suporte ao parecer do auditor, que foram pesquisadas nas empresas de auditoria independente de Santa Catarina, contemplados nos tópicos seguintes.

\section{MÉTODO E TÉCNICAS DA PESQUISA}

A presente pesquisa caracteriza-se como descritiva, de levantamento ou survey e com abordagem quantitativa. A pesquisa descritiva observa, registra, analisa e correlaciona fatos ou fenômenos (variáveis) sem manipulá-los. Procura descobrir, com a precisão possível, a frequência com que o fenômeno ocorre, sua relação e conexão com outros, sua natureza e características". (CERVO e BERVIAN, 2003). Nesse sentido, esta pesquisa procura descrever quais os procedimentos de 
auditoria aplicáveis pelas empresas de auditoria independente de Santa Catarina ao realizarem seus trabalhos em entidades do Terceiro Setor.

Quanto aos procedimentos utilizados, constata-se ser uma pesquisa de levantamento ou survey. Este tipo de pesquisa se caracteriza pela interrogação direta das pessoas cujo comportamento se deseja conhecer. Basicamente, procede-se a solicitação de informações a um grupo significativo de pessoas acerca do problema estudado para em seguida, mediante análise quantitativa, obter as conclusões correspondentes aos dados coletados (GIL, 1999). Nesse contexto, a pesquisa efetuou um levantamento acerca dos procedimentos de auditoria aplicados em entidades do terceiros setor às empresas de auditoria independente estabelecidas em Santa Catarina.

Por fim, quanto à abordagem do problema, a pesquisa caracteriza-se como quantitativa. Aabordagem quantitativa caracteriza-se pelo emprego da quantificação tanto nas modalidades de coleta de informações, quanto no tratamento dessas por meio de técnicas estatísticas, desde as mais simples como percentual, média, desviopadrão, às mais complexas, como coeficiente de correlação, análise de regressão etc. (RICHARDSON, 1989)

O instrumento de coleta de dados consubstancia-se num questionário de 18 perguntas abertas e fechadas. 0 instrumento de pesquisa foi dividido em três partes, sendo: características gerais da empresa de auditoria, identificação das entidades do Terceiro Setor auditadas e os procedimentos de auditadas das demonstrações contábeis aplicados no Terceiro Setor.

A população da pesquisa compreende as empresas de auditoria independente estabelecidas em Santa Catarina com registro na Comissão de Valores Mobiliários (CVM). Em consulta ao sitio da CVM em 29/04/2009, verificou-se um total de 23 empresas cadastradas. 0 contato foi realizado com todas as empresas de auditoria independente por meio de correio eletrônico submetido pelo Conselho Regional de Contabilidade de Santa Catarina (CRC-SC). Nesse e-mail havia a apresentação e a proposta da pesquisa, juntamente com o questionário anexo.

Com apoio do CRC-SC, o questionário foi enviado às empresas de auditoria 3 vezes no período de 27/04/2009 a 05/06/2009, obtendo apenas um retorno. Após passou-se a fazer contato com as empresas de auditoria por telefone. Com esse procedimento foram recebidos mais 8 questionários. Destes 8 questionários recebidos, 3 empresas informaram que não auditam nenhuma entidade do terceiro setor. Assim, das 23 empresas de auditoria independente, participaram da pesquisa 6 empresas, ou seja, uma amostra de 26\%. Foi solicitado que os questionários fossem respondidos por auditores de nível sênior a sócios, devido à necessidade de conhecimento e experiência para o entendimento das questões contidas no instrumento de pesquisa.

Na medida em que os questionários retornavam, os mesmos foram tabulados em planilha eletrônica Excel, para realizar posteriormente a análise e interpretação dos dados da pesquisa. Para analisar os dados utilizou-se da estatística descritiva. 


\section{DESCRIÇÃO E ANÁLISE DOS DADOS}

Inicialmente procurou-se delinear as características das empresas de auditoria de Santa Catarina para entendimento do porte destas empresas. Para tanto, verificouse a quantidade de sócios, número de empregados e tempo de atuação. A Tabela 1 demonstra a quantidade de sócios dentre as empresas de auditoria participantes na pesquisa.

Tabela 1 - Número de sócios

\begin{tabular}{|c|c|c|c|c|c|c|c|c|}
\hline \multirow{2}{*}{ NÚMERO DE SÓCIOS } & \multicolumn{6}{|c|}{ EMPRESAS } & \multirow{2}{*}{$\begin{array}{c}\text { FREQ. } \\
\text { ABS. }\end{array}$} & \multirow{2}{*}{ FREQ. REL. (\%) } \\
\hline & 1 & 2 & 3 & 4 & 5 & 6 & & \\
\hline 2 sócios & & $x$ & & & $x$ & & 2 & $33 \%$ \\
\hline 4 sócios & & & $X$ & & & $X$ & 2 & $33 \%$ \\
\hline 7 sócios & $X$ & & & & & & 1 & $17 \%$ \\
\hline 12 sócios & & & & $\mathrm{X}$ & & & 1 & $17 \%$ \\
\hline
\end{tabular}

Observa-se que duas empresas possuem 2 sócios e outras duas empresas 4 sócios. Destacam-se as empresas 1 e 4 com 7 sócios e 12 sócios respectivamente, pois nas empresas de auditoria, os sócios têm participação ativa nas atividades de condução dos trabalhos, que se somam aos demais recursos profissionais que as empresas possuem, apresentados na Tabela 2.

Tabela 2 - Número de empregados

\begin{tabular}{c|c|c|c|c|c|c}
\hline \multirow{2}{*}{ NÚMERO DE EMPREGADOS } & \multicolumn{3}{|c}{ EMPRESAS } \\
\cline { 2 - 8 } & $\mathbf{1}$ & $\mathbf{2}$ & $\mathbf{3}$ & $\mathbf{4}$ & $\mathbf{5}$ & $\mathbf{6}$ \\
\hline Gerente & $\mathbf{8}$ & 0 & $\mathbf{4}$ & 2 & 0 & 2 \\
\hline Supervisor & 6 & 0 & 0 & 2 & 2 & 2 \\
\hline Sênior & 12 & 1 & 0 & 8 & 1 & 1 \\
\hline Assistente & 42 & 1 & 0 & 20 & 3 & 2 \\
\hline Auxiliar & 20 & 0 & 0 & 6 & 0 & 0 \\
\hline TOTAL & $\mathbf{8 8}$ & $\mathbf{2}$ & $\mathbf{4}$ & $\mathbf{3 8}$ & $\mathbf{6}$ & $\mathbf{7}$ \\
\hline
\end{tabular}

Com a demonstração do número de empregados, novamente observa-se que as empresas 1 e 4 se destacam, não só pela quantidade de empregados, mas pelo número de gerentes, supervisores e seniores que se constituem num recurso mais especializado e necessário às empresas de auditoria independente. Com a demonstração da Tabela 1 e 2 é possível visualizar que as empresas de auditoria de Santa Catarina que participaram da pesquisa, exceto as empresas 1 e 4 , denotam-se empresas de pequeno porte relacionadas ao setor de auditoria.

O tempo de atuação das empresas 1 e 4 são 36 anos e 25 anos respectivamente, enquanto as demais empresas possuem um tempo de atuação de 10 a 13 anos. Somente a empresa 6 , com baixo número de sócios e de empregados, possuem 36 anos de atuação no mercado. Realizada esta caracterização das empresas de auditoria participantes da pesquisa, parti-se para os aspectos relacionados aos procedimentos de auditoria aplicados no terceiro setor. Assim, foram questionados às empresas de auditoria independente de Santa Catarina, quais são as áreas que predominam nas entidades do terceiro setor que são auditadas por elas. 0 resultado deste questionamento é apresentado na Tabela 3. 
Tabela 3 - Áreas de atuação das entidades do terceiro setor auditadas

\begin{tabular}{|c|c|c|c|c|c|c|c|c|}
\hline \multirow{2}{*}{ ÁREA DE ATUAÇÃO DO TERCEIRO SETOR } & \multicolumn{6}{|c|}{ EMPRESAS } & \multirow{2}{*}{$\begin{array}{l}\text { FREQ. } \\
\text { ABS. }\end{array}$} & \multirow{2}{*}{$\begin{array}{l}\text { FREQ. } \\
\text { REL. (\%) }\end{array}$} \\
\hline & 1 & 2 & 3 & 4 & 5 & 6 & & \\
\hline Assistência a Educação & $x$ & $x$ & $x$ & $x$ & $\mathrm{X}$ & $x$ & 6 & $100 \%$ \\
\hline Assistência a Saúde & $x$ & $x$ & & $x$ & $x$ & & 4 & $67 \%$ \\
\hline Esporte & & & $X$ & & & & 1 & $17 \%$ \\
\hline $\begin{array}{c}\text { Estudos e pesquisas, desenvolvimento de tecnologias } \\
\text { alternativas, produção e divulgação de informações e } \\
\text { conhecimentos técnicos e científicos }\end{array}$ & & & & & & $X$ & 1 & $17 \%$ \\
\hline $\begin{array}{c}\text { Experimentação, não lucrativa, de novos modelos sócio- } \\
\text { produtivos e de sistemas alternativos de produção, } \\
\text { comércio, emprego e crédito }\end{array}$ & & $x$ & & $x$ & $\mathrm{X}$ & & 3 & $50 \%$ \\
\hline Organizações políticas & & & & $x$ & & & 1 & $17 \%$ \\
\hline Promoção da assistência social & & & & $x$ & & $\mathrm{X}$ & 2 & $33 \%$ \\
\hline $\begin{array}{c}\text { Promoção da cultura, defesa e conservação do patrimônio } \\
\text { histórico e artístico }\end{array}$ & & & $\mathrm{X}$ & & & & 1 & $17 \%$ \\
\hline $\begin{array}{l}\text { Promoção de ações de prevenção, habilitação e } \\
\text { reabilitáção de pessoas portadoras de deficiências }\end{array}$ & & & & $x$ & & & 1 & $17 \%$ \\
\hline Proteção e amparo a infância e adolescência & $X$ & & & & & $X$ & 2 & $33 \%$ \\
\hline Proteção e amparo a velhice & $x$ & & & $X$ & & & 2 & $33 \%$ \\
\hline
\end{tabular}

Observa-se na Tabela 3, que a área de assistência à educação apresentou uma aderência de $100 \%$, ou seja, todas as empresas de auditoria realizam trabalhos de auditoria das demonstrações contábeis relacionados a esta área. Na sequência, apresenta-se a área de assistência a saúde, com 67\%. Observa-se que as áreas de educação e saúde são áreas em que o setor público ou privado apresentam deficiências, nas quais as entidades do terceiro setor se inserem na contribuição da promoção de mudanças sociais.

Com 50\%, encontram-se as entidades do terceiro setor que promovem o microcrédito que concedem empréstimos de baixo valor a pequenos empreendedores. Numa vertente à assistência social, com 33\% tem-se as entidades com foco na proteção e amparo a crianças e adolescente, à velhice. Por fim, com $17 \%$ encontram-se entidades voltadas ao esporte, estudos e pesquisas, organizações políticas, entidades voltadas à proteção da cultura, defesa e conservação do patrimônio público e de promoção de ações de prevenção, habilitação e reabilitação de pessoas portadoras de deficiências.

Observa-se uma gama de áreas alcançadas pelo terceiro setor, na qual a auditoria das demonstrações contábeis se constitui num processo importante, visto que, a manutenção destas entidades se dá por meio de doações de empresas privadas, públicas e da população geral. A contínua manutenção destas doações ocorrerá na 
medida em que a sociedade perceba lisura na aplicação dos recursos para os fins específicos que tais entidades do terceiro setor foram constituídas.

Como descrito na fundamentação teórica, a auditoria das demonstrações contábeis ocorre por meio de aplicação de procedimentos de auditoria, que se constituem nos testes de observância e dos testes substantivos. A Tabela 4 demonstra quais são os testes de observância mais aplicados pelas empresas de auditoria independente de Santa Catarina ao auditarem as entidades do terceiro setor.

Tabela 4 - Testes de observância mais utilizados pelas empresas de auditoria independente nas entidades do terceiro setor

\begin{tabular}{|c|c|c|c|c|c|c|c|c|}
\hline \multirow{2}{*}{ TESTES DE OBSERVÂNCIA } & \multicolumn{6}{|c|}{ EMPRESAS } & \multirow{2}{*}{$\begin{array}{l}\text { FREQ. } \\
\text { ABS. }\end{array}$} & \multirow{2}{*}{$\begin{array}{l}\text { FREQ. } \\
\text { REL. (\%) }\end{array}$} \\
\hline & 1 & 2 & 3 & 4 & 5 & 6 & & \\
\hline Teste de assinaturas & & $x$ & & $\mathrm{x}$ & & & 2 & $33 \%$ \\
\hline Teste de aprovações & $x$ & $x$ & $x$ & $x$ & & & 4 & $67 \%$ \\
\hline Exame documental & $x$ & $x$ & $x$ & $x$ & $x$ & $x$ & 6 & $100 \%$ \\
\hline Teste de segregação de função & $x$ & $x$ & $x$ & $x$ & $x$ & $x$ & 6 & $100 \%$ \\
\hline Teste de salvaguarda & $x$ & & & & & & 1 & $17 \%$ \\
\hline Integridade de sequência numérica & $x$ & & & & & & 1 & $17 \%$ \\
\hline Cancelamento de documentos & & & $x$ & & & & 1 & $17 \%$ \\
\hline Inquérito: perguntas e respostas & & & & $x$ & $x$ & $x$ & 3 & $50 \%$ \\
\hline Aplicação de questionário & & & $x$ & $x$ & & & 2 & $33 \%$ \\
\hline Conferência de cálculos & & $x$ & & & $x$ & $x$ & 3 & $50 \%$ \\
\hline Exame e contagem física & & & & & $x$ & $x$ & 2 & $33 \%$ \\
\hline
\end{tabular}

Verifica-se na Tabela 4 que os testes de observância mais utilizados são o exame documental e o teste de segregação de funções, utilizado por todas as empresas de auditoria. Outro teste aplicado pelas empresas de auditoria é o teste de aprovações, com 67\%. Inquérito e conferência de cálculos apresentam-se com $50 \%$. Estes dois testes chamam a atenção pelo fato que ambos são aplicados a todo instante pelo auditor, pois a cada momento são realizados conferências de cálculos e se realizam questionamentos aos auditados. Os testes com menor utilização pelas empresas de auditoria são o teste de salvaguarda, o teste de integridade de sequência numérica e o cancelamento de documentos.

Cunha, Beuren e Hein (2006) realizam uma pesquisa similar em que se verificaram os procedimentos de auditoria mais utilizados pelas empresas de auditoria de Santa Catarina, cujo foco não foram as entidades do terceiro setor. Os resultados dessa pesquisa, quando verificados os testes de observância, convergiram com os aplicados nas entidades do terceiro setor: o exame documental e o teste de segregação de funções. Outra convergência ocorreu aos testes menos aplicados: teste de salvaguarda, o teste de integridade de sequência numérica e o cancelamento de documentos. Infere-se que as empresas de auditoria de Santa Catarina, no que se trata da aplicação dos testes de observância não se diferenciam quanto à aplicação dos testes de observância em empresas do terceiro setor ou empresas constituídas sob outras formas jurídicas. Na sequência, efetua-se a análise 
dos testes substantivos, demonstrados na Tabela 5.

Tabela 5 - Testes substantivos mais utilizados pelas empresas de auditoria independente nas entidades do terceiro setor

\begin{tabular}{|c|c|c|c|c|c|c|c|c|}
\hline \multirow{2}{*}{ TESTES DE SUBSTANTIVOS } & \multicolumn{6}{|c|}{ EMPRESAS } & \multirow{2}{*}{$\begin{array}{c}\text { FREQ. } \\
\text { ABS. }\end{array}$} & \multirow{2}{*}{$\begin{array}{l}\text { FREQ. } \\
\text { REL. (\%) }\end{array}$} \\
\hline & 1 & 2 & 3 & 4 & 5 & 6 & & \\
\hline Exame e contagem física & $\mathrm{X}$ & $\mathrm{X}$ & $\mathrm{X}$ & $\mathrm{X}$ & & $\mathrm{X}$ & 5 & $83 \%$ \\
\hline Confirmação externa (circularização) & $\mathrm{X}$ & $\mathrm{X}$ & $\mathrm{X}$ & $\mathrm{X}$ & $\mathrm{X}$ & $\mathrm{X}$ & 6 & $100 \%$ \\
\hline Conciliações & & $\mathrm{X}$ & $\mathrm{X}$ & $\mathrm{X}$ & & $X$ & 4 & $67 \%$ \\
\hline Exame de documentos originais & $\mathrm{X}$ & & $\mathrm{X}$ & $\mathrm{X}$ & $\mathrm{X}$ & $X$ & 5 & $83 \%$ \\
\hline Conferência de cálculos & $X$ & & $\mathrm{X}$ & $X$ & & & 3 & $50 \%$ \\
\hline Exame de escrituração & $\mathrm{X}$ & $\mathrm{X}$ & & $\mathrm{X}$ & $\mathrm{X}$ & $\mathrm{X}$ & 5 & $83 \%$ \\
\hline Exame de registros auxiliares & & & & & $\mathrm{X}$ & & 1 & $17 \%$ \\
\hline Inquérito: perguntas e respostas & & & & $\mathrm{X}$ & & & 1 & $17 \%$ \\
\hline Investigação minuciosa & & & & & & & 0 & $0 \%$ \\
\hline Correlação das informações obtidas & & $\mathrm{X}$ & & & $X$ & & 2 & $33 \%$ \\
\hline Observacão & & & & $\mathrm{X}$ & & & 1 & $17 \%$ \\
\hline
\end{tabular}

Evidencia-se na Tabela 5 que os testes substantivos mais utilizados são a confirmação externa, com 100\% e exame e contagem física, o exame de documentos originais e o exame de escrituração, com $83 \%$ cada. Os testes substantivos menos utilizados pelas empresas de auditoria foram o exame de registros auxiliares, o inquérito e a observação, todos com $17 \%$, seguido pelo teste de investigação minuciosa, sem nenhuma indicação pelas empresas de auditoria.

Ao comparar com a pesquisa de Cunha, Beuren e Hein (2006), apresentouse convergência no procedimento de confirmação externa. Estes autores também identificam as conciliações e a conferência de cálculos, juntamente com a confirmação externa, com os procedimentos mais utilizados, em que nesta pesquisa apresentaramse com $67 \%$ e $50 \%$ respectivamente. Nos procedimentos menos utilizados nos testes substantivos, Cunha, Beuren e Hein (2006) também identificam os procedimentos de observação e de investigação minuciosa, ou seja, observa-se que não há diferença de aplicação de testes pelas empresas de auditoria ao se auditar entidades do terceiro setor. Observados os testes de auditoria mais aplicados, na sequência são evidenciados em que áreas estes testes são mais aplicados. A Tabela 6 demonstra em quais áreas os testes de observância tem maior aplicação.

Tabela 6 - Áreas com maiores aplicações dos testes de observância

\begin{tabular}{|c|c|c|c|c|c|c|c|c|}
\hline \multirow{2}{*}{ ÁREAS DE AUDITORIA } & \multicolumn{6}{|c|}{ EMPRESAS } & \multirow{2}{*}{$\begin{array}{c}\text { FREQ. } \\
\text { ABS. }\end{array}$} & \multirow{2}{*}{$\begin{array}{l}\text { FREQ. } \\
\text { REL. }(\%\end{array}$} \\
\hline & 1 & 2 & 3 & 4 & 5 & 6 & & \\
\hline Disponibilidades & & & & $\mathrm{x}$ & $\mathrm{X}$ & $\mathrm{X}$ & 3 & $50 \%$ \\
\hline Contas a receber & $\mathrm{X}$ & $\mathrm{X}$ & & & & $\mathrm{X}$ & 3 & $50 \%$ \\
\hline Estoques & $\mathrm{X}$ & $\mathrm{X}$ & & & & $\mathrm{X}$ & 3 & $50 \%$ \\
\hline Ativo Imobilizado & & & & & & & 0 & $0 \%$ \\
\hline Fornecedores & & $\mathrm{X}$ & & & $X$ & $\mathrm{X}$ & 3 & $50 \%$ \\
\hline Financiamentos & & & & & & & 0 & $0 \%$ \\
\hline Patrimônio social & & & & & & & 0 & $0 \%$ \\
\hline Vendas & $x$ & $\mathrm{X}$ & $\mathrm{X}$ & & & & 3 & $50 \%$ \\
\hline Compras & $\mathrm{X}$ & $\mathrm{X}$ & $\mathrm{X}$ & $\mathrm{X}$ & $\mathrm{X}$ & & 5 & $83 \%$ \\
\hline Pessoal & $\mathrm{X}$ & $\mathrm{X}$ & & $x$ & $\mathrm{X}$ & $\mathrm{X}$ & 5 & $83 \%$ \\
\hline Despesas gerais & & & & $\mathrm{X}$ & & & 1 & $17 \%$ \\
\hline Doações e subvenções & & & $\mathrm{x}$ & $\mathrm{X}$ & & & 2 & $33 \%$ \\
\hline
\end{tabular}


A Tabela 6 demonstra que com 83\%, nas áreas de compras e de pessoal são mais aplicados os testes de observância. De forma oposta, as áreas de ativo imobilizado, financiamentos e patrimônio social foram as áreas sem menção de aplicação dos testes de observância pelas empresas de auditoria.

Na pesquisa de Cunha, Beuren e Hein (2006) apresenta-se a área de pessoal também como a área que mais utiliza os testes de observância e a área do ativo imobilizado, dos financiamentos e do patrimônio líquido como as áreas com menor aplicação. Observa-se novamente uma convergência nos achados entre as duas pesquisas. Com o mesmo intuito, na Tabela 7, demonstram-se as áreas que mais utilizam os testes substantivos.

Tabela 7 - Áreas com maiores aplicações dos testes substantivos

\begin{tabular}{|c|c|c|c|c|c|c|c|c|}
\hline \multirow{2}{*}{ ÁREAS DE AUDITORIA } & \multicolumn{6}{|c|}{ EMPRESAS } & \multirow{2}{*}{$\begin{array}{c}\text { FREQ. } \\
\text { ABS. }\end{array}$} & \multirow{2}{*}{$\begin{array}{l}\text { FREQ. } \\
\text { REL. (\%) }\end{array}$} \\
\hline & 1 & 2 & 3 & 4 & 5 & 6 & & \\
\hline Disponibilidades & $X$ & $X$ & $x$ & $X$ & $X$ & $\mathrm{X}$ & 6 & $100 \%$ \\
\hline Contas a receber & $X$ & $X$ & $x$ & & $X$ & $\mathrm{X}$ & 5 & $83 \%$ \\
\hline Estoques & $X$ & $X$ & $\mathrm{X}$ & $\mathrm{X}$ & $X$ & $\mathrm{X}$ & 6 & $100 \%$ \\
\hline Investimentos & & & $\mathrm{X}$ & & $X$ & & 2 & $33 \%$ \\
\hline Ativo Imobilizado & $\mathrm{X}$ & $\mathrm{X}$ & & & & & 2 & $33 \%$ \\
\hline Exigibilidades & & $\mathrm{X}$ & & $\mathrm{X}$ & $\mathrm{X}$ & $\mathrm{X}$ & 4 & $67 \%$ \\
\hline Patrimônio social & & & & & & & 0 & $0 \%$ \\
\hline Receitas & $\mathrm{X}$ & & & & & $\mathrm{X}$ & 2 & $33 \%$ \\
\hline Custos e despesas & $\mathrm{X}$ & & & $\mathrm{X}$ & & & 2 & $33 \%$ \\
\hline Doações e subvenções & & & & $x$ & & & 1 & $17 \%$ \\
\hline
\end{tabular}

A Tabela 7 revela que os testes substantivos são mais utilizados pela auditoria independente nas áreas relacionadas com as disponibilidades e com os estoques, com $100 \%$ cada. A área das contas a receber também se apresentou com uma área em que os testes substantivos são utilizados, com $83 \%$. Justifica-se este resultado pelo fato de que os testes substantivos têm como intuito detectar desvios materiais nas classes de transações e nas demonstrações contábeis e as áreas das disponibilidades e das contas a receber devem ser constantemente monitoradas, pois parte destes recursos advém de doações e a aplicação dos mesmos devem ser adequados, de forma prudente e com transparência. Na pesquisa de Cunha, Beuren e Hein (2006), as disponibilidades e as contas foram às áreas com maior aplicação dos testes substantivos, ou seja, os resultados entre as pesquisas são convergentes.

Observa-se, no entanto, que as doações e subvenções, com 17\% e o patrimônio social, sem nenhuma menção, apresentam-se como as áreas com menor aplicação dos testes substantivos. Em relação às doações e subvenções, este resultado vai de encontro ao exposto no parágrafo anterior. Na comparação com a pesquisa de Cunha, Beuren e Hein (2006), o patrimônio líquido também se apresentou o a menor aplicação dos testes substantivos.

$\mathrm{Na}$ pesquisa também foi solicitados aos respondentes que informassem, mediante pergunta aberta, segundo suas opiniões, quais são as áreas ou aspectos que necessitam de maior atenção e de maior tempo do auditor para validação dos 
controles ou saldos. Os resultados são demonstrados na Tabela 8.

\section{Tabela 8 - Áreas prioritárias na auditoria das demonstrações contábeis nas entidades do terceiro setor}

\begin{tabular}{|c|c|c|c|c|c|c|c|c|}
\hline \multirow{2}{*}{ ÁREAS/ASPECTOS PRIORITÁRIOS } & \multicolumn{6}{|c|}{ EMPRESAS } & \multirow{2}{*}{$\begin{array}{l}\text { FREQ. } \\
\text { ABS. }\end{array}$} & \multirow{2}{*}{$\begin{array}{l}\text { FREQ. } \\
\text { REL. }(\%\end{array}$} \\
\hline & 1 & 2 & 3 & 4 & 5 & 6 & & \\
\hline Aplicação de recursos & $x$ & & $x$ & $\mathrm{x}$ & & & 3 & $50 \%$ \\
\hline $\begin{array}{l}\text { Análise da aplicação dos níveis mínimos } \\
\text { de gratuidade }\end{array}$ & & $\mathrm{x}$ & & & $\mathrm{X}$ & & 2 & $33 \%$ \\
\hline Contas a receber & & $x$ & & & $x$ & & 2 & $33 \%$ \\
\hline Disponibilidades & & $\mathrm{X}$ & & & & $\mathrm{X}$ & 2 & $33 \%$ \\
\hline $\begin{array}{c}\text { Análise estatutária e sustentação } \\
\text { jurídica }\end{array}$ & & $\mathrm{x}$ & & & & & 1 & $17 \%$ \\
\hline $\begin{array}{l}\text { Atendimentos as disposiccões legais e } \\
\text { cumprimento das obrigaçoes acessórias }\end{array}$ & & & & $\mathrm{x}$ & & & 1 & $17 \%$ \\
\hline $\begin{array}{l}\text { Baixas e operações, niveis de } \\
\text { provisionamento, (entidade de } \\
\text { microcrédito) }\end{array}$ & & $\mathrm{X}$ & & & & & 1 & $17 \%$ \\
\hline Doações e subvenções & & & & $\mathrm{X}$ & & & 1 & $17 \%$ \\
\hline Empréstimos e financiamentos & & & & & $\mathrm{X}$ & & 1 & $17 \%$ \\
\hline Fornecedores & & & & & $\mathrm{X}$ & & 1 & $17 \%$ \\
\hline $\begin{array}{l}\text { Operações de crédito em aberto } \\
\text { (entidade de microcrédito) }\end{array}$ & & $\mathrm{X}$ & & & & & 1 & $17 \%$ \\
\hline Passivos contingentes & & $\mathrm{X}$ & & & & & 1 & $17 \%$ \\
\hline
\end{tabular}

Os resultados da Tabela 8 ratificam os achados anteriormente na pesquisa. Observa-se que a aplicação de recursos, com $50 \%$ e as contas a receber e as disponibilidades, cada um com 33\%, são considerados itens importantes de auditoria pelos auditores. Neste contexto, os auditores também mencionam com 33\%, a análise da aplicação dos níveis mínimos de gratuidade, que devem ser observados para que as entidades do terceiro setor mantenham sua condição de filantropia e gozem de suas isenções tributárias. Outro aspecto de interesse na pesquisa, evidenciado na Tabela 9, foi a identificação de quais legislações os auditores independentes utilizam nas auditorias das demonstrações contábeis, visto as especificidades que o terceiros setor possui.

Tabela 9 - Legislações norteadoras na auditoria em entidades do terceiro setor

\begin{tabular}{|c|c|c|c|c|c|c|c|c|}
\hline \multirow{2}{*}{ LEGISLAÇÃO } & \multicolumn{6}{|c|}{ EMPRESAS } & \multirow{2}{*}{$\begin{array}{l}\text { FREQ. } \\
\text { ABS. }\end{array}$} & \multirow{2}{*}{$\begin{array}{c}\text { FREQ. REL. } \\
\text { (\%) }\end{array}$} \\
\hline & 1 & 2 & 3 & 4 & 5 & 6 & & \\
\hline Legislações específicas do terceiro setor & $x$ & & & $\mathrm{X}$ & $\mathrm{x}$ & & 3 & $60 \%$ \\
\hline $\begin{array}{r}\text { Normas emanadas pelo Conselho Federal de } \\
\text { Contabilidade - CFC }\end{array}$ & $x$ & & & $x$ & $\mathrm{X}$ & & 3 & $60 \%$ \\
\hline Legislação trabalhistas e tributária & & & & $x$ & & & 1 & $20 \%$ \\
\hline Lei $11.941 / 2009$ & & $x$ & & & & & 1 & $20 \%$ \\
\hline $\begin{array}{l}\text { Normas emanadas pelo Comitê de } \\
\text { Pronunciamentos Contábeis - CPC }\end{array}$ & & $\mathrm{x}$ & & & & & 1 & $20 \%$ \\
\hline $\begin{array}{l}\text { Normas emanadas pelo Instituo dos Auditores } \\
\text { Independentes do Brasil - IBRACON }\end{array}$ & $\mathrm{x}$ & & & & & & 1 & $20 \%$ \\
\hline Regulamento do Imposto de Renda - RIR/99 & & & & $x$ & & & 1 & $20 \%$ \\
\hline Resolução 877/2000 e 926/2001 do CFC & & $\mathrm{x}$ & & & & & 1 & $20 \%$ \\
\hline
\end{tabular}


Conforme observado na Tabela 9, das seis empresas participantes da pesquisa, duas não responderam a este questionamento. Dentre as quatro empresas respondentes, as legislações específicas do terceiro setor e as normas emanadas pelo Conselho Federal de Contabilidade apresentaram $60 \%$ das respostas. Verifica-se que as respostas apresentam-se de forma ampla, sem especificar a lei ou as normas do CFC especificamente. Outras respostas generalizadas, com percentual menor também foram apresentadas, como normas emanadas pelo IBRACON e a legislação trabalhista e tributária.

De forma específica, foram mencionadas as Resoluções 877/2000 e 926/2001 do CFC, que tratam especificamente de aspectos contábeis de entidades sem fim lucro. O Regulamento do Imposto de Renda também foi citado, bem como a lei 11.941 de 2009, que altera a legislação tributária federal relativa ao parcelamento ordinário de débitos tributários, concede remissão nos casos em que especifica e institui regime tributário de transição.

\section{CONCLUSÃO}

O objetivo do artigo foi identificar quais são os procedimentos de auditoria utilizados pelas empresas de auditoria independente estabelecidas em Santa Catarina nas entidades do Terceiro Setor. Assim, realizou-se uma pesquisa descritiva, de levantamento e com abordagem quantitativa, com as empresas de auditoria independente de Santa Catarina que realizam trabalhos de auditoria das demonstrações contábeis de entidades do terceiro setor.

$\mathrm{Na}$ auditoria das demonstrações contábeis os auditores utilizam de diversos procedimentos de auditoria para assegurar que as demonstrações contábeis representam adequadamente, em seus aspectos relevantes, a situação econômica e patrimonial das entidades. Esses procedimentos compõem-se dos testes de observância e dos testes substantivos.

Constatou-se que os testes de observância mais utilizados pelas empresas de auditoria independente de Santa Catarina são o exame documental e o teste de segregação de funções, utilizado por todas as empresas de auditoria. 0 exame documental convergiu com o esperado, enquanto que o exame físico apresentou somente $33 \%$ de indicação como procedimento mais utilizado. Já os testes com menor utilização pelas empresas de auditoria são o teste de salvaguarda, o teste de integridade de sequência numérica e o cancelamento de documentos.

Verificou-se que as áreas de compras e de pessoal são as áreas com maior aplicação dos testes de observância, enquanto que nas áreas de ativo imobilizado, financiamentos e patrimônio social o resultado foi oposto. Verifica-se que as doações e subvenções não se apresentaram como a área de maior aplicação dos testes de observância conforme o esperado.

Quanto aos testes substantivos mais utilizados, constatou-se que são os 
testes de confirmação externa, o exame e contagem física, o exame de documentos originais e o exame de escrituração. O teste de confirmação externa confirmou-se com o esperado, com $100 \%$ de aplicação pelas empresas de auditoria pesquisadas. Os exames de contagem física, de documentos originais e de escrituração, com 83\%, entende-se também que se aproximou do esperado na pesquisa.

Com menor utilização pelas empresas de auditoria independente de Santa Catarina apresentam-se o exame de registros auxiliares, o inquérito e a observação e o teste de investigação minuciosa.

As áreas com maior aplicação dos testes substantivos foram as áreas relacionadas com as disponibilidades, com os estoques e com as contas a receber. Num resultado contrário, as doações e subvenções e o patrimônio social apresentam-se como as áreas com menor aplicação dos testes substantivos. Contatou-se que o resultado relacionado com as disponibilidades foi atingido, contudo, as doações e subvenções apresentaram-se opostas aos resultados esperados na pesquisa.

Concluiu-se também que os resultados desta pesquisa convergiram com a pesquisa de Cunha, Beuren e Hein (2006) nos aspectos relacionados aos testes mais e menos utilizados, e nas áreas que mais e menos são aplicados estes procedimentos de auditoria, tanto para os testes de observância quanto aos substantivos. Isso demonstra que para as empresas de auditoria de Santa Catarina que participaram da pesquisa, os procedimentos de auditoria aplicados não diferem pelo fato de se constituir numa auditoria das demonstrações contábeis com foco no terceiro setor em relação aos outros setores.

\section{REFERÊNCIAS}

ALBUQUERQUE, Lúcia Silva. O nível de evidenciação das informações contábeis geradas pelas organizações da sociedade civil de interesse público - OSCIP do Estado da Paraíba. 2007. 130 fls. Dissertação (Mestrado em Ciências Contábeis) Dissertação (Mestrado em ciências Contábeis), Programa Multiinstitucional e Inter-Regional de Pós-Graduação em Ciências Contábeis - UnB, UFPB, UFPE e UFRN, Brasília, 2007.

ANDRADE, Lucila Carmélia de. Técnicas de amostragem em empresas de auditoria na cidade do Rio de Janeiro: um estudo de casos. 1988. 188f. Dissertação (Mestrado em Ciências Contábeis) - Instituto Superior de Estudos de Estudos Contábeis - ISEC Fundação Getúlio Vargas, Rio de Janeiro, 1988.

ATTIE, William. Auditoria: conceitos e aplicações. 5.ed. São Paulo: Atlas, 1998.

BARRAGAN, Luciana Gavazzi. Controle interno: diagnóstico e adaptação para entidades do terceiro setor. 2005. 175 fls. Dissertação (Mestrado em Controladoria e Contabilidade Estratégica) - Centro Universitário Álvares Penteado (UNIFECAP), São Paulo, 2005. 
BOYNTON, William C.; JOHNSON, Raymond N.; KELL, Walter G. Auditoria. Tradução: José Evaristo do Santos. São Paulo: Atlas, 2002.

BRASIL. Decreto no 2.536, de 06 de abril de 1998. Dispõe sobre a concessão do Certificado de Entidade de Fins Filantrópicos a que se refere o inciso IV do art. 18 da . Lei $n^{\circ}$ 8.742, de 7 de dezembro de 1993, e dá outras providências. Brasília - DF. Disponível em:< http://www.planalto.gov.br/ccivil_03/decreto/d2536.htm.> Acesso em: 01 jun. 2009.

. Lei n 9.790, de 23 de março de 1999. Dispõe sobre a qualificação de pessoas jurídicas de direito privado, sem fins lucrativos, como Organizações da Sociedade Civil de Interesse Público, institui e disciplina o Termo de Parceria, e dá outras providências. Brasília - DF. Disponível em:<http://www.planalto.gov.br/ccivil/LEIS/ L9790.htm> Acesso em: 01 jun. 2009.

CERVO, Amando L.; BERVIAN, Pedro A. Metodologia científica. 5.ed. São Paulo: Prentice Hall, 2003.

COMISSÃO DE VALORES MOBILIÁRIOS. Disponível em: <http:/cvm.org.br>. Acesso em: 29 abr. 2009.

CONSELHO FEDERAL DE CONTABILIDADE. Resolução CFC n 820, de 17 de dezembro de 1997. Aprova a NBC T 11 - Normas de Auditoria Independente das Demonstrações Contábeis com alterações e dá outras providências. Acesso em: <http://www.cfc. org.br/sisweb/sre/docs/RES_820.doc>.

Resolução CFC n 1.214, de 27 de novembro de 2009. Aprova a NBC TA 330 Resposta do Auditor aos Riscos Avaliados. Acesso em: <http://www.cfc.org.br/sisweb /sre/detalhes_sre.aspx?Codigo=2009/001214>.

CUNHA, Paulo Roberto da; BEUREN, Ilse Maria; HEIN, Nelson. Procedimentos de auditoria independente utilizados pelas empresas de auditoria independente estabelecidas em Santa Catarina. Revista Base, São Leopoldo, v. 3, n. 1, p. 53-62. jan/abr. - 2006.

GIL, Antonio Carlos. Métodos e técnicas de pesquisa social. 5.ed. São Paulo: Atlas, 1999.

INSTITUTO BRASILEIRO DE GEOGRAFIA E ESTATÍSTICA. As fundações privadas e associações sem fins lucrativos no Brasil. 2.ed. Rio de Janeiro: 2004.

IMONIANA, Joshua Onome. Auditoria: abordagem contemporânea. São Paulo: Associação de Ensino de Itapetininga, 2001.

KPMG AUDITORES INDEPENDENTES. Auditoria externa do terceiro setor. 2004. Disponível em: www.kpmg.com.br/images/P7602-Office-Palestra.pdf>. Acesso em: 10 jun. 2009.

. Auditoria externa do terceiro setor. 2006. Disponível em: http: //www.kpmg. com.br/publicacoes/audit/terceiro_setor_Auditoria_no_Terceiro_Setor.pdf> Acesso 
em: 10 jun. 2009.

LIMA, Welington de Pontes. Controles internos e riscos de auditoria: influência na extensão dos testes substantivos em auditoria das demonstrações contábeis. 2002. 132 fls. Dissertação (Mestrado em Controladoria e Contabilidade) da Faculdade de Economia, Administração e Contabilidade da Universidade de São Paulo, São Paulo, 2002.

MESSIER JR, William F. Auditing \& Assurance Services: a systematic approach. $3^{\text {rd }}$ edition. McGraw-Hill: New York, 2003.

OLAK, Paulo Arnaldo; NASCIMENTO, Diogo Toledo do. Contabilidade para entidades sem fins lucrativos: terceiro setor. Atlas: São Paulo, 2006.

RENGEL, Silene et al. Importância do balanço social para as entidades do terceiro setor sob a ótica dos gestores das APAES da Região do Alto Vale do Itajaí/SC. In.: SEMEAD, XII., 2009, São Paulo. Anais... São Paulo: SEMEAS, 2009.

RICHARDSON, Roberto Jarry. Pesquisa social: métodos e técnicas. 2.ed. São Paulo: Atlas, 1989.

SANTI, Paulo Adolpho. Introdução à auditoria. São Paulo: Atlas, 1988.

SOARES, Euvaldo Antonio Ruiz. Entidades beneficentes de assistência social educacionais: uma investigação sobre a medição de desempenho organizacional. 2006. 131 fls. Dissertação (Mestrado em Ciências Contábeis) Dissertação (Mestrado em Ciências Contábeis), Programa Multiinstitucional e Inter-Regional de Pós-Graduação em Ciências Contábeis - UnB, UFPB, UFPE e UFRN, Brasília, 2006. 


\section{DADOS DOS AUTORES:}

\section{Paulo Roberto da Cunha}

Universidade do Estado de Santa Catarina, Centro de Educação Superior do Alto Vale do Itajaí - CEAVI

Rua Dr. Getúlio Vargas, 2822 - Bela Vista

Ibirama, SC - Brasil

89140-000

\section{Roberto Carlos Klann}

Fundação Educacional de Brusque, Centro Universitário de Brusque Unifebe Curso de Ciências Contábeis.

Rua Dorval Luz, 647 - Santa Terezinha

Brusque, SC - Brasil

$88352-400$

\section{Silene Rengel}

Conteg Contabilidade s/s Ltda.
Al. Aristiliano Ramos, 900 - Sala 302 - Centro
Rio do Sul, SC - Brasil
89160-000

Jorge Eduardo Scarpin

Fundação Universidade Regional de Blumenau, Programa de Pós Graduação em Ciências Contábeis.

Rua Antônio da Veiga, 140 - Victor Konder

Blumenau, SC - Brasil

89012-900 